\title{
An Integrated Resource Platform for Visual Basic Programming Language Course*
}

\author{
Xiuying Wang ${ }^{1}$, Fang Zhou ${ }^{2}$ \\ ${ }^{1}$ The College of Information Science and Technology, Qingdao University of Science and Technology, Qingdao 266000, China \\ ${ }^{2}$ Department of Computer Science, Qindao College, Qingdao, 266106, China \\ bywxy@126.com, xiaowuyu1230@gmail.com
}

\begin{abstract}
An integrated resource platform for visual basic programming language courses (VBPLC) was studied and developed to meet the needs of top quality course construction based on integrated method of Dreamweaver, ASP and fireworks. In this paper, we analysis firstly that the platform should has functions and performance, and its structure and functions are designed in detail. The platform main includes course construction achievements, message board and online testing system (OTS). Through more than two years application, it is demonstrated that platform works stability and reliability, improving students and teachers message exchange, and reached goal of sharing top quality course resources.
\end{abstract}

Index Terms - Integrated resource platform, Visual Basic programming language (VBPLC), top quality course, ASP, Dreamweaver.

\section{Introduction}

In 2003, China's Ministry of Education began to work on teaching quality and teaching reform project to cultivate qualified college students to meet national development needs, to improve students international competitiveness, to reinforce using information technology in the teaching process, to make students learn initiatively and independently, to closely combine theory with practice and so on. The notice of educational ministry pointed out that the top quality course is model curriculum with some features such as first-class teachers, first-class teaching content, first-class teaching methods, first-class materials, and first-class teaching management [1].

The notice from Ministry of Education received national colleges and universities' extensive support and earnest implement. Qingdao University of Science and Technology (QUST) started and carried out work on excellent course construction in 2004[2]. Some courses are appraised and elected as university-level excellent courses from qualified and experienced teachers, who have been teaching for long time, with good teaching effect. Visual basic programming language (VBPLC) was evaluated as excellent course of QUST in 2006 because of its teaching effects and good teachers, and it was evaluated as top quality course of QUST in 2008. The excellent course construction for many years let us know that top quality course is a long-term job.

As the excellent course construction goes further, teachers and students are realizing it is very important that excellent teaching resources be shared in top quality course construction. To achieve this point, an integration platform must be set up and we need to make effort toward this goal in a long run. Teachers need to plan thoughtfully before they start integrating the curriculum resources [3].

In 2006, the early days of VBPLC construction, we put emphasis on teaching contents, teaching methods and the core resources of teaching-learning process. The core resources include VBPLC introduction, teaching outline, teaching calendar, teaching program or presentations, teaching plans, the homework of students, references index and so on. These resources had been integrated into Web Site of QUST for students to download and use freely.

Because of college teachers adopt flexible working time, it is impossible that students meet the teacher everyday. Thus, the problems that student can't understand about what they learned in their class can't be resolved timely. In 2008, we developed a website of VB excellent course; there is communication in website to solve the above problems [4]. After the students login, they can put their problems into message board. Every day there would be a teacher to answer students' questions at any time, and promptly submit answer to the online platform for the questions asked by online students and other students.

In 2010, for assessing students' command of know they're being taught on VBPLC, we developed an online testing system (OTS)[5]. OTS is an important part of the construction of excellent courses, and an effective way of student selftesting.

Presently the known online testing system mostly includes the functions such as random generation of test papers, automatic grading and so on. The functions are basically identical to the examination system. Among them, the characteristic of reference [6] is containing the subjective questions test. But the test results or scores could be gained by the teachers grading, which can not meet the students' needs of self-testing after class. The characteristics of reference [7] is we can get the average score after the test and the proportion of band scores distribution according to need, which provides the evaluation basis for teachers but this is meaningless for the students' self-testing their learning effect. The difference between [8] and the former is the timing function added, which

\footnotetext{
* This work is supported by Shandong Province Higher Educational Teaching Reform Project(2012275) and Shandong Province Graduate Educational Innovation Project(SDYY11048).
} 
is used to monitor the test time. Reference [9] is developed based on B/S structure. With the strategy of generating a test paper on the average difficulty level, it makes questions of different difficulty levels hold reasonable proportion in the test paper. But this algorithm is insufficient in that a sufficient number of questions need to be provided in question bank for running selection algorithm. Otherwise, the test papers extracted each time would be similar, which will limit students test range of knowledge. Reference [10] is difference in that a paper integral analysis module is added. A premise condition of using the module is the number of the test participants must reach the predetermined sample size. Otherwise, analysis is not preceded. This method has practical significance to group evaluation, but can't evaluate individual student's master of knowledge. Reference [11] is different in that the user can, according to his need, choose types and number of questions to generate the papers. This kind of tests is a comprehensive test for the course. However, for the students who are learning this course a gradual process is lacked.

The online testing systems which are researched and developed by the existing documents function similarly to the examination system. However they should have different functions: (1) In the exam system students are not allowed to know the scores immediately after examination, while online testing system allows students to know scores and answers immediately, namely doing and knowing. (2) The exam system does not need to offer students analysis, while test system should offer answers and analysis for every exam in order to let the students know how and why. (3) The exam is a comprehensive review of the students after learning the course, in which the global distribution of exam questions should be taken into account, and unlearned content shouldn't appear in the paper. However, testing system must be set according to chapters or sections, or step by step. Some questions aiming at improvement of the students' self-study level can also be added.

Because of these reasons, we designed and developed An OTS. It includes the two parts: chapter test and comprehensive test. In chapter test, an analysis function is attached. The analysis function is not only to give student answer, correct or erroneous on the test, but also to provide the reasons why he makes such a mistake. Students can not only know why they are wrong, but they can also know what causes error and thus master the knowledge more efficiently. In comprehensive test, new function is attached. The function automatically filters out examination questions that student answered correctly in last test. Thus, students all do new examination questions and examination questions that student answered wrong in last test when they have re-tested, don't waste their test time. Moreover, there is a management module in OTS, which enables the administrator to increase test content, check, and delete operation. Teachers also can to update and modify the content of the test and the high-quality goods curriculum.

In this paper, we will introduce the developed and integrated platform of VBPLC quality course resources. The platform mainly includes course construction achievements for many years, message board and online test system.

\section{The Function and Performance Requirement Analysis of Integration Platform}

\section{A. Requirement Analysis of Functions}

The interface of platform should be beautiful, generous, the overall style harmonious and unified; navigation is distinct, the operation is simple and convenient for teacher and student.

Pictures, animation and so on should have subject characteristics. Students will find it is the interest and appreciation when they are browsing platform.

The platform should provide rich learning resources and have a search function to assist students' autonomous learning and to find the needed materials in time [12].

The platform should have a communication block. As college teachers adopt flexible working time, it is impossible that students meet teacher everyday. Thus, the problems that student can't understand about what they have learned in their class can't be resolved timely. So, a message board must be provided. As long as they have access to internet, their problems can be submitted to the platform.

Students hope test their learning knowledge level after they have learned a chapter. Another to test students ability to use learning knowledge synthetically, also need to provide comprehensive testing function.

\section{B. Requirement Analysis of Performances}

When processing data, the platform should have good accuracy and timeliness. When querying data, the platform should be ensured the keyword in the corresponding record that can be found in the corresponding data range ensure platform to long-term, reliable and efficient operation, the platform also have the following performance requirements:

The platform has good extensibility. Construction of excellent course is a long-term teaching task, which is needed to update and perfect new content of curriculum construction. So platform is requested that it should have enough space to adjust and expand functions of construction course needed.

\section{Structure and Function of Platform}

\section{A. Platform Structure}

The purpose of research and development the platform is accumulated many years teaching results to students and convenience teachers and students using. First, top quality course platform must show the teaching information of this course, including course description, teaching team, course results, experiments and papers questions, teaching courseware, instructional videos, etc. Then, it is convenient for the teacher-student interchanges, a communication area (message board) is provided to facilitate the students to practice and self-test, the platform also need to provide a test system, its overall structure is shown in Fig 1. 


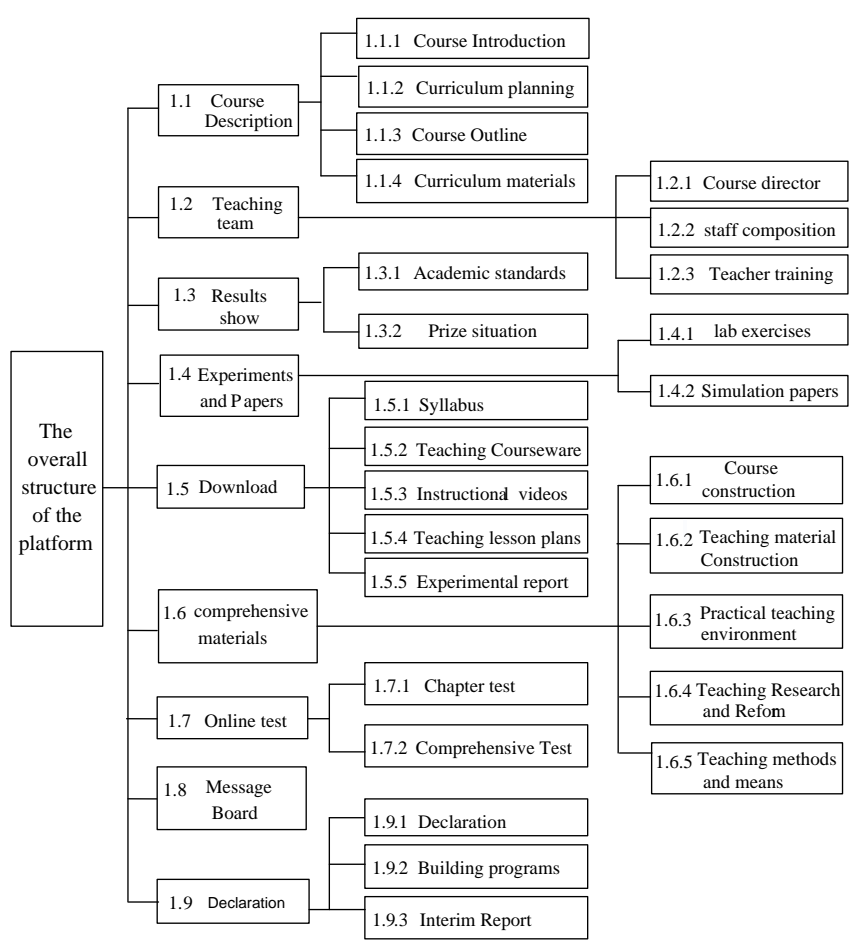

Fig. 1 Structure of Platform

\section{B. Function}

The platform is composed of nine parts: course introduction, teaching team, the results show, experiments and papers, downloads synthetic materials, online testing, message boards and declaration, used to display the relevant content of courses, the main function of each module is described as below:

1) Course Introduction: It's mainly to introduce VBPLC, which consists of four parts: course description, curriculum planning, syllabus and teaching materials. The content of each part exist in a single page, design simple text links on the page, and the text that can be returned to its superior columns or the home page, also the design of a tree in the left navigation webpage, convenient for the user to view the content selection.

2) Teaching team: The course director, team members constitute teacher training display on the page.

3) Results show: The part will display the related research projects and awards which get from course director and the team teachers; it is divided to two parts: the academic level and the results show, which will be the teacher of the awards made into flash for displaying, is to increase the page.

4) Experiments and papers: VBPLC not only theoretical teaching content, but also assisted experiment teaching. Here mainly to show experimental contents, operation requirements, and operating process of reference on the page; simultaneously with previous examination questions and experimental practice questions.

5) Downloads: This module provides the VBPLC's teaching outline, teaching courseware, electronic lesson plans, teaching the students experiment report and some teaching video, for users to download.
6) Composited materials: This module includes the excellent course construction, teaching material construction, the implementation of practical teaching, teaching research and reform and teachers' teaching methods, etc.

7) Message board: mainly provides the online communication between teachers and students.

8) Online testing: this module mainly plays four roles: chapters test, comprehensive test, the scores query and exit system.

9) Declaration: Show the relevant documents of the course in the reporting process; mainly include the declaration, construction scheme, interim report and supporting materials.

\section{The Realization of Platform}

The message board and implementation see paper [4]. We introduce most difficult implementation parts of the platform.

\section{A. Implementation process of platform and corresponding codes}

One of the most difficult parts is positioning of homepage elements. If it was not designed and developed well, once switch the browsers, you would found these elements running to the other position. This problem was solved by repeated practice and test absolute positioning.

Absolute positioning method is $\mathrm{H} 3$ (position: absolute; TOP 100px). The advantage of using the absolute positioning is element can be precisely controlled in any position. It can be removed from its original position, and repositioned in any position expected and moved to the specified location, which controls the elements of the origin, so absolutely positioned elements will not bring any influence, next to the elements in the page.

In this paper, homepage use nine div-tags to layout. First, add a big div (id for main), and set the width attribute. Then the other div should be nested in them, specifying the width and height respectively. The main code is as follows:

\section{- Nested div Code}

$<$ div id="main" >

$\langle$ div id="kecheng" $>$

$<\mathrm{a}$ href="kcjs.html" class="more" $>$ kecheng $</ \mathrm{a}>$

$<$ p align="justify" class="kengcheng_p" $>\ldots</$ p $>$

$</$ div $>$

$\langle$ div id="kaoshi" $>$

\section{- Set the Attribute Code}

\#main \{

background-image: url(/imgs/main.gif);

background-repeat: no-repeat;

margin: 0px;

padding: 0px;

height: 532px;

width: 948px;

position: relative;

\}

In the use of nested div, absolute positioning is a very useful feature, if a container is absolutely positioned elements 
positioning, then specifies the top and left for the element value will no longer be based on the root HTML page, which is the top left corner of the page, and will be calculated based on the left corner of the container, such as with id "kaoshi" nested div.It's positioned as follows:

\#main \#kaoshi \{

margin: 0px;

padding: 0px;

height: 254px;

width: 309px;

position: absolute;

top: 10px;

right: 11px;

\}

The starting position of the div is calculated based on this container at the upper left of the main, the implementation of other nested div method, only need to measure the size of the good parts in the design drawing, can very well determine the starting location of div elements in the finished page orientation, so as to complete the layout of the home page.

\section{B. Realization of the analysis function online test systems}

The analysis function in the chapter tests module is another difficult implementation in this system. In the existing test systems, students can only see test scores or questions right or wrong after test, but they cannot know why has caused this mistake. So the existing testing system can't meet the students' requirements. In order to make students find their shortage in learning in time and strengthen their understanding of relevant concepts, this module provides error analysis function. When the student answers a question incorrectly, the system will provide a detailed analysis of the question, which can effectively help the student understand the knowledge point in the question and deepen their understanding of this knowledge point, so that the student knows the hows and whys.

TABLE I Table Structure of "db_Onlinetest. Mdf"

\begin{tabular}{|l|l|c|l|c|l|}
\hline \multicolumn{1}{|c|}{ Field names } & $\begin{array}{c}\text { Data } \\
\text { type }\end{array}$ & Length & Defaults & NULL & Field Description \\
\hline ID & bigint & 8 & & No & the only mark \\
\hline sj_zhuti & varchar & $\max$ & & Yes & questions theme \\
\hline sj_leixing & char & 10 & & Yes & questions type \\
\hline sj_tiankongqian & varchar & $\max$ & & Yes & forepart of gapfill \\
\hline sj_tiankonghou & varchar & $\max$ & & Yes & backpart of gapfill \\
\hline sj_jiarushijian & datetime & 8 & $\begin{array}{c}\text { Get__ } \\
\text { date() }\end{array}$ & Yes & $\begin{array}{l}\text { adding time } \\
\text { of question }\end{array}$ \\
\hline sj_zhangjiehao & int & 4 & & Yes & $\begin{array}{l}\text { subordinate } \\
\text { section }\end{array}$ \\
\hline sj_A & varchar & 100 & & Yes & option A \\
\hline sj_B & varchar & 100 & & Yes & option B \\
\hline sj_C & varchar & 100 & & Yes & option C \\
\hline sj_D & varchar & 100 & & Yes & option D \\
\hline sj_daan & varchar & 50 & & Yes & question's answer \\
\hline sj_fenxi & varchar & $\max$ & & Yes & analysis \\
\hline sj_zhushi & varchar & 50 & & Yes & comments \\
\hline
\end{tabular}

According to the requirement of the system design, the design of the database in this system adopts SQL Server 2005, and it is named "db_onlinetest. mdf". The six tables is designed in the database:tb_chengji, tb_guanli, tb_shijuan, tb_taoti, tb_xuesheng and tb_zhangjie, which are separately used to store the relevant data for the system. The date structure is showed in Table I. The Realization code please see paper[5].

\section{Conclusion}

In this paper, we introduced the structure of an integration resource platform for VBPLC. The platform was developed on the basis of ASP, Dreamweaver and fireworks integrated technologies. Interface of platform is clear, warm and comfortable. The platform has many functions such as teaching and learning, teachers and students interaction, online testing and so on. As the platform has been in use for years, the results of application show that the system has stably run and has good expansion and teaching resources are rich, whose function satisfy demands of teachers and students. It has achieved the aim that resource be shared freely. But top quality course construction is a long-term job. With the continuous demand for top quality course construction, platform will be modified to meet the growing demand of teaching and learning for teachers and students.

\section{References}

[1] Http://www.jpkcnet.com/new/zhengce/Announces_detail.asp?Announce s_ID $=13$.

[2] Http://jpkc.qust.edu.cn/index/kcjs.asp.

[3] Q. Wang, "A generic model for guiding the integration of ICT into teaching and learning", Innovations in Education and Teaching International, vol. 45, no.3, pp.411-419, 2008.

[4] X. Y. Wang, Y. M. Sui, and M. H. Liu, "The Design and Realization of VB Excellent Course Website", The 19th International Conference on Industrial Engineering and Engineering Management, Changsha, China, October 2012, pp.1245-1252.

[5] X. Y. Wang and F Zhou, "The Online Testing System With Explain Function As Students Answer Mistake," IEEE International Symposium on IT Medicine and Education, Guangzhou,China, vol.2, pp. 456-460, December 2011.

[6] Liu Yongli, "The design and implementation of the online testing system" , China Education Informationization, pp.47-48, February 2007

[7] Z.G. Wang, "The Design and Implementation of ASP.NET-based online testing system", Computer Engineering and Design, vol.28, no.5, pp. 1166-1168, March 2007.

[8] Y. Zhang, X.H. Xia, and H. C. Tan, "The design and implementation of the online testing system of acupuncture course", Computer knowledge and technology, vol.6, no.3, pp.638-640, January 2010.

[9] L. L. Cai, X. M. Li, and D. C. Chao, "The design and implementation of the online testing system based on B/S structure", Journal of Henan normal university (Natural Science), vol.35, no.2, pp.181-182, 186, May 2007.

[10] Y. Wang, Z. J. Bai, Y. B. Cheng, and W. Liu. "The design of the Network course online testing system". Chinese Medical Education Technology, vol.18, no.2, pp.118-120, April 2004.

[11] C. Hua, X. F. Sun, "Network course online testing system", Journal of Suzhou Vocational University, vol.17, no.5, pp.39-42, November 2006.

[12] L. L Lohr, "Designing the instructional interface", Computers in Human Behavior, vol. 16, pp.161-182, 2000. 